Kappa $=0.47 ; 95 \%$ CI $[0.17,0.77])$. Only $63.1 \%$ of IC tertile scores agreed with that quoted at the initial MDT. This improved to $82.3 \%$ when comparing to tertile 1 vs tertile 2 or 3 .

Conclusion Overall we demonstrated only fair to modest repeatability in SS calculation amongst individual ICs. This is similar to findings in other studies, though it is known improvements are possible with intensive training (2). We advise that significant variability in SS calculations should be considered within all institutions unless validated training systems are in place. In the absence of these systems we suggest the weight of importance attributed to quoted SS in MDT decision making should be guarded.

\section{OUTCOMES OF ACCESS SITE IN PATIENTS WITH STEMI}

D Ranganathan, R Howley, P O'Connor, P Kearney. Cork University Hospital, Cork, Ireland

\subsection{6/heartjn|-2020-ICS.31}

Introduction Current ESC Guidelines (2017) recommends radial access over femoral access (Class 1A ) during primary PCI for STEMI. However, radial access can be technically more challenging, particularly in older patients, smaller patients and females in whom the radial artery may be small and brachiaand brachocephalic tortuously is frequently encountered. This may delay re-perfusion, and increase radiation exposure.

Aim We aimed to analyse real-world clinical data on the choice of access site with success of intervention, complications rate and radiation exposure in patients presenting with STEMI.

Methods We retrospectively evaluated 227 patients presenting to Cork University Hospital between January 2019 to December 2019 with a ST-elevation myocardial infarction. 58 patients were excluded due to lack of sufficient data and the remaining 169 patients were compared based on their access site.

Observed variables included success of intervention, allcause mortality, complication rate and radiation exposure. Outcomes of patients operated via the radial approach versus the femoral approach was compared using Chi-Square. We used SPSS for all statistical analysis and p-values of $<0.05$ was considered to be statistically significant.

Results The demographics of the 169 patients analysed are described (table 1). 120 patients $(71 \%)$ had a radial artery for access of which 7 patients transitioned to an alternative access site (5 patients to right femoral artery and 2 patients to left radial artery).

Of the 49 patients in femoral access site, 6 patients had no palpable right radial pulse/Barbeau's test negative, 5 were anticipated to require intra-aortic balloon pump/temporary wire insertion and 1 had flexure contracture of right arm from previous stroke. Of 5 patients in the left radial access, 2 had previous $C A B G, 2$ had no palpable right radial pulse and 1 had AV fistula involving right forearm.

Fourteen patients were thrombolysed at another centre, 1 brought for immediate PPCI despite successful lysis and 13 required rescue PCI. There were 3 unsuccessful cases between the 2 groups (p-valve 0.283 ). The patients with graft study in each group had successful interventions regardless of access site. When comparing radiation exposure, there was no significant difference between radial and femoral
Abstract 31 Table 1 Baseline characteristics, procedural data, and outcomes

\begin{tabular}{|c|c|c|}
\hline & $\begin{array}{l}\text { Radial }(n=120)-5 \\
\text { changeover to femoral } \\
\text { access }\end{array}$ & Femoral $(n=49)$ \\
\hline Age & 61.8 & 65.3 \\
\hline Males & 100 & 39 \\
\hline BMI & 28.9 & 27.3 \\
\hline HTN & 46 & 24 \\
\hline Dyslipidaemia & 37 & 19 \\
\hline DM & 23 & 10 \\
\hline Current smoker & 40 & 16 \\
\hline Thrombolysis & $\begin{array}{c}11 \\
\text { Failed: } 10\end{array}$ & $\stackrel{3}{\text { Failed }: 3}$ \\
\hline Left sided access & 5 & None \\
\hline Graft studies & 2 & 3 \\
\hline Culprit vessel & $\begin{array}{c}\text { RCA: } 47 \\
\text { LMS: } 2 \\
\text { LAD: } 49 \\
\text { LCX/Rl: } 18 \\
\text { Graft: } 1 \\
\text { No intervention: } 3\end{array}$ & $\begin{array}{lc}- & \text { RCA: } 27 \\
- & \text { LMS: } 1 \\
- & \text { LAD: } 18 \\
- & \text { LCX: } 2 \\
- & \text { Graft: } 1 \\
- & \text { No intervention: } 0\end{array}$ \\
\hline $\begin{array}{l}\text { Rate of unsuccessful } \\
\text { intervention }\end{array}$ & 3 & 3 \\
\hline Mean fluoroscope time & 12.42 & 12.01 \\
\hline $\begin{array}{l}\text { Mean Dose area product } \\
\text { (mGycm2) }\end{array}$ & 55,432 & 45,351 \\
\hline $\begin{array}{l}\text { Average change in creatinine } \\
\text { pre/1-day post angiogram }\end{array}$ & $14 \%$ increase & $23 \%$ increase \\
\hline Complications & $\begin{array}{cc}- & 1 \text { Stroke } \\
- & 1 \text { Acute kidney injury }\end{array}$ & $\begin{array}{l}\text { - } 1 \text { Retro-peritoneal bleed } \\
\text { - } \quad 3 \text { Acute kidney injury }\end{array}$ \\
\hline Mortality & $4(3.33 \%)$ & $6(12 \%)$ \\
\hline
\end{tabular}

access on fluoroscopy timing and dose area product ( $\mathrm{p}$-value $0.2425)$. There was a higher average creatinine rise associated with femoral access, possibly a consequence of higher contrast volume. In regard to complications, there was higher mortality risk associated with femoral access (p-value 0.038) and complication rates ( $p$-value 0.048 ) and significant overall adverse outcomes (p-value 0.005986) compared to radial access.

Conclusion Complication rates were very low, but our study findings support previous studies, such as MATRIX, RIFLESTEACS and RIVAL, with regard to lower vascular complications associated with radial access. The study revealed similar radiation exposure levels between the 2 access sites.

\section{General poster session}

\section{IMAGE NOT IMAGINE. POCUS AND DISCHARGE DECISION MAKING IN HOSPITALIZED PATIENTS WITH HEART FAILURE}

L O'Toole, P Sharma, M Malik, S Rummun, S Fleming. Midlands Regional Hospital, Portlaoise, Co. Laois, Ireland

\subsection{6/heartjnl-2020-ICS.32}

Introduction Among patients hospitalized with heart failure (HF), residual congestion (RC) at discharge is common and predicts rehospitalization and death at 6 months. Clinical assessment of congestion is challenging particularly for hospitalized patients as they near discharge. Point of Care Ultrasound (POCUS) is an emerging modality offering advantages of accessibility and convenience over traditional imaging 